Daily the bird visited the garden till the bushes were cleared, and so the crop was saved. In Crowle this year these birds are numerous. I have a garden in a place in North Wales where this year there are few of these birds. The grub stripped the bushes of leaves, and the fruit died.

Worcester, June 23.

J. Lloyd-Bozward.

On the Diselectrification of Metals and other Bodies by Light.

REFERRING to a footnote on page 135 of NATURE, June 7 , Messrs. Elster and Geitel have been good enough to call my attention to a great deal of work done by them in the same direction and published in recent numbers of Viedemann's Annalen. The most important statement about it is that they had observed the photoelectric power of fluorescent minerals and the electrical activity of sunlight, and had worked for some time at the influence of these facts on atmospheric electrification; the idea that atmospheric electricity was thus caused (by the discharging action of sunlight) having been already mooted apparently by von Bezold and Arrhenius.

Oliver J. Lodge.

\section{Absence of Butterflies.}

IT may be worth while to put on record what has happened this spring and summer, viz. the total absence of butterfiy life. Beyond an occasional white butterfly, there are none to be seen. I have a large garden where there is usually abundance of them, but a coloured butterfly has not been seen this year yet.

Gravesend, July 2.

Delta.

\section{THE SETTLEMENT OF THE EPPING FOREST QUESTION. ${ }^{1}$}

BY a happy coincidence the Essc $x$ Naturalist, containing the full official report of the discussion on the management of Epping Forest, which took place under the auspices of the Essex Field Club on April 28, 2 and the Report of the experts appointed by the Corporation of London, have been published almost simultaneously, the former having been issued a fortnight or so before the latter. As the proceedings of the Conservators had been subjected to a running fire of the most vehement criticism ever since last autumn, the question of the management of the forest may be considered to have excited an amount of popular interest such as had never before been raised since the public dedication by the Queen in 1882 . The reason for the popular outburst of indignation on the present occasion is to be found in the circumstance that the thinning operations had been carried on in a district which is well known to contain the finest example of a beech wood that the forest offers, viz. Monk Wood, and the amassed heaps of felled trunks, drawn to the roadside for removal, naturally attracted the attention of every passer-by, and gave rise to a not altogether unnatural feeling of uneasiness as to the fate of the forest's show woodland. A fair and unbiassed examination of Monk Wood, however, soon sufficed to dispel any fears of unnecessary destruction or permanent injury, and those whose judgment in such matters is worthy of the most serious attention, did not hesitate to express their bolief that the operations had on the whole been carried out judiciously, and for the future benefit of the forest. This conclusion was arrived at in many cases against the preconceived notions of some of the visitors who attended the meeting on April 2 8 , and some speakers in the discussion with great candour admitted that the result of the visitation and the explanations given on the spot had been to cause them to modify their views. This

1 "The Essex Naturalist, being the Joumal of the Essex Field Ciub, edited by William Cole. Hon. Sec. Nos. $1-5$, vol. viii., published Jun 1894. "Eppinz Forest, Keport of Experts as to Management, Sc. Reprrt, Epping Forest Committee." presented June 14. 1894

NO. I 288 , vol. 50] appears most distinctly from the speeches of such wellknown friends of the forest as Sir Frederick Young, Prof. Boulger, and Mr. F. C. Gould, and it is only fair to add that many others who, without any special knowledge of forestal operations, attended the meeting, of which the proceedings are now reported, as lovers of the naturally picturesque, had their judgment materially aided by the opportunity given them for comparing portions of the forest which had been severely thinned in former years with other portions which had not yet been attacked. The arguments for and against the conservatorial doings are fully set forth in the Essex Naturalist, and will form an important chapter in the bistory of the forest management.

But the Essex Field Club has of course no official connection with the Epping Forest Committee, and although, as everybody knows, the chief executive verderer is Mr. Edward North Buxton, this gentleman gave his services as a conductor of the meeting because of his special knowledge on the one hand, and on the other as an officer of the Field Club. The decision at which the meeting arrived, as already reported in these columns, is in no sense an official utterance of the Club as a body corporate, but is simply to be regarded as an expression of individual opinions consequent upon a personal visitation and a discussion raised thereby. It seems desirable to make this statement in order to avoid future misunderstanding.

The Corporation of London, as the official Conservators of the forest, on April 12 appointed a special Committee of experts, in their own words, "to view the forest, and advise us forthwith as to the effect of the thinning, and our future policy with regard to the management of the forest." The names suggested were Viscount Powerscourt, Dr. Schlich (the Professor of Forestry at Cooper's Hill), Mr. James Anderson of Manchester, and Mr. William Robinson, the edifor of the Garden. Sir Joseph Hooker was also asked to nominate two other members, and he suggested the names of Earl Ducie, Mr. A. B. Freeman-Mitford, M.P. (formerly Secretary to H.M. Commissioners of Works), and Mr. Angus D. Webster, formerly forester to the Duke of Bedford. Lords Ducie and Powerscourt were unable to join the Committee, but the five signatures attached to the Report may be considered as strongly representative of the art and science of forestry as the names of any committee of experts that has ever been or possibly could be brought together in this country.

Taking the Report as a whole, it will be seen that the Committee practically give their sanction to the policy which has been, and is being, pursued by the Conservators, and endorse the decision arrived at by the majority of those who took part in the meeting and discussion on April 28. Surely after this most weighty verdict there need be no further alarm as to the future of the forest. A detailed analysis of the Report would occupy too much space in these columns, but some of the most important recommendations mav be considered. And first of all, with respect to the opening out of views and the making of clearings, there is no uncertainty about their statement :-

"As there is much beautiful landscape in and around the forest, the opening up of which would add much to its charms, we think that the best views should be carefully opened up by making judicious clearings. Such views would be in every way a gain. .... The rides and drives are beautiful features of the forest, and those made in recent years are well designed. They should receive constant attention, lest the encroachments of vegetation should mar their picturesque effect. In this connection we would call attention to the beauty of the glades which already exist. These should be increased in number, where it can be done without sacrificing the finer trees, or interfering with the massive groups of the forest." 
With respect to the thinning out of superfluous trees, the Commissioners touch upon a point of considerable importance :-

"A vast proportion of the area of the forest is covered by pollard hornbeams. In parts they are an interesting feature; but the practice of pollarding having been discontinued, the trees are now so deise that neither light nor air can penetrate. IVe consider that, with a view to encouraging the growth of better trees and varying the monotony of the forest, the best course will be, not generally to thin the trees, but to make bold clearances among them. The finer pollard oaks throughout the forest should be carefully preserved."

The importance of this recommendation lies in the circumstance that such a large area of the forest is covered by pollard hornbeams, often most unsightly through overcrowding, while pollard oaks, and especially such as could fairly be called "fine," are comparatively scarce. There are very few naturally-grown hornbeams throughout the forest area, and it is to be noted with satisfaction that the policy adopted by the Conservators, and further enforced by this recommendation of the experts, will give an opportunity for developing the natural growth of a tree which is an almost unique feature of the forest. The writer is not acquainted with any woodland in this country where the hornbeam forms such a prominent feature.

The Conmittee lay stress upon the importance of preserving the "massive character of the forest," and this also is a point on which it appears necessary to make some observations. Where the trees admit of being "massed," as the beeches in Monk's IVood, or the oaks in Hawk Wood, this policy would naturally find favour. But discretion has been, and no doubt will be, shown in this direction. A large number of trees might advantageously be removed from such an area as Hawk Wood without destroying its massiveness; and yet, when the Conservators come to deal with this part of the forest, there will no doubt be another outcry. WVith respect to this area the Committee state:-

"Hawk IVood is in the main an oak wood, and the trees are not such as would be improved by wholesale thinning. It would be, in our opinion, wise to take out no trees except such as are obviously dying, and a few scrubby stunted trees which are injuring the others. Where, here and there, a single specimen of more than usual beauty can be encouraged into noble growth, it should be protected from overcrowding."

This is precisely what the Conservators proposed to do with Hawk IVood before the present agitation, and a very good suggestion has been made that the chairman of the Committee of experts should be invited to go over this wood and mark the trees which he would recommend to be removed. The Conservators have already marked the trees which they proposed to remove. A comparison of the results would be a most practical lesson in forestry, and, so far as the writer is acquainted with Hawk Wood (which is very thoroughly), it may be safely affirmed that there would be no very serious division of opinion between the chairman and the verderers.

In connection with the question of encouraging the growth of underwood the Committee "do not think that in all parts sacrifices should be made for the purpose of encouraging it where the trees do not allow of its healthy growth, as under beeches." This observation no doubt applies more especially to Monk IVood, and so far may be claimed as a ratification of the work done there. The thinning cannot in this district be fairly considered to have led to any serious sacrifices of good trees, and a ramble through that woodland will convince the lover of the picturesque that the massiveness has not been interfered with. In view of the circumstance that the public attention was first drawn to the recent thinnings by the operations in this district, it is to be regretted that the No. [ 239, voc. 50] experts have not expressed themselves more fully on this point. They express no disapproval of what has been done, but they consider that the thinnings will be sufficient "for many years to come," an observation which will no doubt be fully concurred in by the Conservators. There was never any intention expressed of thinning further in this woodland for the present.

The Committee recommend also that the trees in High Beech should not be interfered with, that the hollies in WValthamstow IVood should be allowed to develop by removing the dead or dying trees or the pollards which are interfering with them, and that the "healthy oaks, even where crowded, should be left standing. The beauty of tall oak stems, often lichen. covered, when growing in close woods, should be considered." In connection with this last remark it may be interesting to add that for some reason or another lichens refuse to flourish on the trees in Epping Forestcertainly in the lower forest, and the hoary trunks which are such delightful features of the Kentish and Surrey woods are unknown in the southern portions of the forest. In Theydon High Wood "moderate and periodic thinning "is recommended. In Lord's Bushes it is recommended that the young trees should be allowed to take the lead, and only the "finer and more picturesque pollards" preserved. All these recommendations are, it will be seen, substantially in accord with the line of action pursued by the Conservators.

The followirg suggestion with respect to drainage will give extreme satisfaction to naturalists :-

"We consider that there should be as little artificial drainage as possible, though in the case of rides or drives it is sometimes necessary. The natural drainage is in most places sufficient, and the streamlets should be allowed to make their own courses."

Another recommendation, which we endorse most heartily, is that "it may be necessary for a time to protect certain spaces against the inroads of cattle, horses, and deer."

The experts are opposed to artificial planting in general, and are in favour of letting nature do her own planting, excepting in cases where tree growth is insufficient, when they recommend that the seed of indigenous trees should be introduced. Four of the Commissioners are even opposed to having a nursery, but Dr. Schlich does not agree with this. In view of the fact that a large area of forest land was fornerly under cultivation, and has only been thrown open in recent years, we are disposed to agree with Dr. Schlich. None of us will ever live to see these tracts restored to anything like a natural condition unless planting is resorted to.

Taking the Report in its entirety, it may be said that the question of the management of Epping Forest is now settled beyond cavil, and settled in a manner calculated to give strength to the hands of the Conservators and to reassure the public. The ridiculous exaggeration of seekers after cheap notoriety may in future be allowed to pass by unheeded. As Sir John Lubbock said in his late address to the Selborne Society :- "A great debt of gratitude was due to the conservators and verderers of the forest "; and again in the Times of June I :- "IVe are greatly indebted to the Corporation of London, to Mr. Buxton and his colleagues, and . . Epping Forest will be even more beautiful fifty years hence than it is now." The Report of the experts concludes with the very pregnant paragraph :-

"In conclusion, we may say that we are not prepared to endorse the strictures which have been passed upon the work carried out in Epping Forest. IVe are of opinion that much has been done judiciously and well. In some instances we should not, perhaps, unanimously approve of the whole of the action of the authorities. In others, we may consider that more might have been done. But of one thing we are certain, that whatever 
has been done has been animated by earnest desire to preserve the finest features of the forest, and through intimate knowledge of its necessities and peculiar conditions."

R. MELDOLA.

\section{NOTES.}

THE meeting held on Saturday last at the Royal College of Physicians, and reported in the Times, was a very satisfactory one. It was attended by delegates from nearly all the institutions which it was proposed, in the report of the late Royal Commission on the Gresham University, should form constituent colleges of the reorganised University of Lonion. Dr. Russell Reynolds, F.R.S., occupied the chair. Since Sir Albert Rollit gave notice in the House of Commons of a motion asking that some action be taken to carry into effect the report of the Royal Commission, there has been ample time for the various institutions involved in the scheme for a Teaching University to deliberate and deliver their opinions on the recommendations. Practically all the constituent schools and colleges have availed themselves of the opportunity, and have, in the main, expressed approval of the proposals. The time has arrived, therefore, at which to set the machinety in action which would lead the Government to appoint a Statutory Commission to frame a scheme on the lines of the report of the late Commission. The necessary motive power is contained in the following resolutions put before Saturday's meeting. It was moved by Prof. Erichsen, the president of University College, and seconded by the Rev. Mr. Whitehouse- "That this meeting of delegates from institutions mentioned in the report of the Royal Commission on the Gresham University desires to express generally its approval of the proposals contained in the report of the Royal Commission, and would urge on the Government that a Statutory Commission be appointed at an early date with power to frame statutes and ordinances in general conformity with the report of the Royal Commission." This resolution was put to the meeting and was carried, the only dissentients being the representatives of King's College. It was also agreed, on the motion of Dr. Norman Moore, "That a copy of this resolution be forwarded to the Lord Chancellor, the Lord President of the Privy Council, the Home Secretary, and the Vice-President of the Council, to be accompanied by a request that they will receive a deputation on the subject, the same to consist of the delegates to this meeting."

PAST and present students of the Mason College, Birming. ham, presented Dr. Tilden with a silver bowl and a congratula. tory address last week, on his removal to the chair of Chemistry at the Royal College of Science, and as a mark of appreciation of his long and honourable career in connection with the college. The proceedings were of a very enthusiastic character, and Dr. Tilden's students and colleagues vied with each other in expressing their esteem for him as a teacher and an investigator. In the course of his reply, Dr. Tilden re. marked that fourteen years ago he went to Birmingham quite a stranger, at a time when there was no science college actually opened. His three colleagues-Profs. Hill, Poynting, and Bridge-were appointed with him as the first four professors of the college, when the building was quite empty. In the first session they had some eighty students between them, and those days were exceedingly happy. Those first professors had unusual privileges and responsibilities. They were naturally given a free hand. They had no traditions to live up to, no standard to go by except that which theg themselves set up. They were entrusted with the great duty, the heavy responsibility, of creating their several departments and building up the life of the college, and setting up standards of teaching and conduct which would serve for their successors. Referring to his NO. I 288 , VOL. 50] successor, Dr. Tilden said that, under Prof. Percy Irankland's care, he had no doubt that the work of the college would advance in the right direction.

OUR continental neighbours must often he amused at the forms in which we raise monuments. It will be remembered that a year ago a subscription list was opened for the purpose of erecting a memorial of some kind to Gilbert White. The appeal resulted in $£ 250$ being obtained. With this money a hydraulic ram has been fixed at the spring head near the village of Selborne, to force water into a reservoir erected eighty feet above the village. The water runs from the reservoir through pipes laid along the main streets, and tapped at convenient intervals. Selbornites are thus enabled to obtain a supply of water without journeying to the fountain at the spring head, as had previously to be done. This useful and unpretentious memorial is in keeping with Gilbert White's character; nevertheless, it seems to us that the committee having the funds at their disposal should also have taken into consideration the fact that he does not belong to Selborne alone, but to all lovers of nature.

WE learn from the British Medical fournal that three further remarkable instances of the success of Prof. Haffkine's system of anticholera inoculation are reported from Calcutta. In the first case, four out of the six members of a family were inoculated last March. The cholera appeared in the neigh. bourhood lately, and the disease attacked one of the two who had not been inoculated, while the inoculated remained free. In the second case, five members of a family consisting of eleven persons were inoculated in March. The cholera lately attacked one of the six who had not been inoculated. In the third case, six out of a family of nine were inoculated. When the cholera prevailed in the neighbourhood a few days later the disease attacked one of the three not inosulated. It is stated that the Corporation of Madras have passed a resolution inviting Prof. Haflkine to visit that city and introduce his system.

Trie Council of the Royal Statistical Society announce that the subject of the essays for the Howard Medal, which will be awarded in 1895 with $20 l$. as heretofore, is as follows:- " $\mathrm{Re}$ formatories, and industrial schools of that class, in their relation to the antecedents, crimes, punishments, education after conviction, and training of juvenile offenders: together with the nature and extent of their influence on the diminution or increase of crime generally. These particulars have to be collected and analysed on a statistical basis, both as respects the institu. tions and agencies, public and private, at home and abroad, for the reclamation of juvenile offenders, and the best means of dealing with them on release. This does not include the industrial and training institutions certified by the Local Government Board under the 25 and 26 Vict. cap. 43." The essays should be sent in on or before June 30,1895 .

THE death is announced of Prof. F. Q. Rodriguez, Professor of Crystallography in the University of Madrid.

Dr. Josepir Coats has been appointed Professor of Pathology in the University of Glasgow.

Mr. L. O. HowaRD has been appointed entomologist to the U.S. Department of Agriculture, in succession to Prof. C. V. Riley.

MR. J. WoLfe BARRY, the engineer of the Tower Bridge, has had the honour of the Companionship of the Bath conferred upon him by the Queen.

Prof. W. ERB, of Heidelberg University, and F. Jolly, of Berlin, representing an influential committee, invite subscriptions for the erection of a monument to the late Dr. Charcot in the Salpêtrière. 